\title{
Japan Diabetes Outcome Intervention Trial-1 (J-DOIT1), a nationwide cluster randomized trial of type 2 diabetes prevention by telephone- delivered lifestyle support for high-risk subjects detected at health checkups: rationale, design, and recruitment
}

\author{
Naoki Sakane ${ }^{1 *}$, Kazuhiko Kotani ${ }^{1}$, Kaoru Takahashi ${ }^{1,2}$, Yoshiko Sano ${ }^{1}$, Kokoro Tsuzaki $^{1}$, Kentaro Okazaki ${ }^{1}$, \\ Juichi Sato ${ }^{3}$, Sadao Suzuki ${ }^{4}$, Satoshi Morita ${ }^{5}$, Kazuo Izumi ${ }^{6,7}$, Masayuki Kato ${ }^{6}$, Naoki Ishizuka ${ }^{8}$, \\ Mitsuhiko Noda $a^{6,7,9}$ and Hideshi Kuzuya ${ }^{1,10}$
}

\begin{abstract}
Background: Lifestyle modifications are considered the most effective means of delaying or preventing the development of type 2 diabetes (T2DM). To contain the growing population of T2DM, it is critical to clarify effective and efficient settings for intervention and modalities for intervention delivery with a wide population reach. The Japan Diabetes Outcome Intervention Trial-1 (J-DOIT1) is a cluster randomized controlled trial to test whether goal-focused lifestyle coaching delivered by telephone can prevent the development of T2DM in high-risk individuals in a real-world setting. This paper describes the study design and recruitment of the study subjects.

Methods: For the recruitment of study subjects and their follow-up annually over 3 years, we employed health checkups conducted annually at communities and worksites. Health care divisions recruited from communities and companies across Japan formed groups as a cluster randomization unit. Candidates for the study, aged 20-65 years with fasting plasma glucose (FPG) of 5.6-6.9 mmol/l, were recruited from each group using health checkups results in 2006. Goal-focused lifestyle support is delivered by healthcare providers via telephone over a one-year period. Study subjects will be followed-up for three years by annual health checkups. Primary outcome is the development of diabetes defined as FPG $\geq 7.0 \mathrm{mmol} / \mathrm{I}$ on annual health checkup or based on self-report, which is confirmed by referring to medical cards.
\end{abstract}

Results: Forty-three groups (clusters), formed from 17 health care divisions, were randomly assigned to an intervention arm (22 groups) or control arm (21 clusters) between March 2007 and February 2008. A total of 2840 participants, 1336 from the intervention and 1504 from the control arm, were recruited. Consent rate was about $20 \%$, with no difference between the intervention and control arms. There were no differences in cluster size and characteristics of cluster between the groups. There were no differences in individual characteristics between the study arms.

(Continued on next page)

\footnotetext{
* Correspondence: nsakane@kyotolan.hosp.go.jp

'Division of Preventive Medicine, Clinical Research Institute, National Hospital

Organization Kyoto Medical Center, Kyoto, Japan

Full list of author information is available at the end of the article
} 
(Continued from previous page)

Conclusion: We have launched J-DOIT1, a nation-wide trial to prevent the development of T2DM in high-risk individuals using telephone-delivered intervention. This trial is expected to contribute to evidence-based real-world preventive practices.

Trial registration : UMIN000000662.

\section{Background}

Type 2 diabetes mellitus (T2DM) is rapidly becoming one of the major health issues of the $21^{\text {st }}$ century $[1,2]$. A recent survey performed by the Ministry of Health, Labour and Welfare has projected that approximately 8.9 million people have diabetes and another 13.2 million people are at high risk for diabetes in Japan [3,4]. There is an urgent need for effective strategies to combat this pandemic. The Finnish Diabetes Prevention Study (DPS) [5] and US Diabetes Prevention Program (DPP) [6] both clearly showed that intensive lifestyle intervention can prevent or delay the development of T2DM in a high-risk population. Thus, lifestyle modifications are considered the most effective means of delaying or preventing the development of T2DM $[7,8]$. The DPP and DPS interventions have been translated into church [9], weight loss clinic [10], YMCA [11], primary care [12], and community [13] settings. However, translating the findings of clinical research, such as the DPS and DPP, into a real-world practice [14] on a large-scale still remains to be addressed. Japan has adopted the universal medical care insurance system, where all the people are insured by one of the public medical insurance systems [15,16]. In 2003 the Health Promotion Law was enforced aiming at preventing lifestyle-related diseases including T2DM. Now it has become mandatory for all Japanese adults to undergo health checkups provided by public medical care insurance at least once a year. There are two main types of statutory health checkup programs; 1) workplace health checkup programs managed by employers (companies setting), and 2) community health checkup programs managed by municipalities (communities setting) for self-employed, unemployed and retired individuals. People are registered at health care divisions in their workplaces or communities, and through the health care divisions, health checkups are provided. Health checkups are becoming part of routine health care. As a whole about $50 \%$ of adults undergo health check-ups annually. A large number of high-risk subjects for diabetes are identified every year through these health checkups. It is questionable, however, to what extent annual health checkups contribute toward overcoming the pandemic of diabetes. There is a big gap between identifying high risk subjects and preventing diabetes in the real world. One of the reasons for this may be a lack of evidencebased effective and efficient prevention programs which are easily accessible. The Japan Diabetes Outcome intervention Trial-1 (J-DOIT1) is a nation-wide, cluster randomized controlled trial [17], aiming to establish effective and efficient programs to prevent the development of T2DM in high-risk individuals through lifestyle modifications. The cluster randomization design has the advantages of administrative convenience, ease of obtaining the cooperation of investigators, enhancement of subject compliance, and avoidance of treatment contamination [18]. Health care divisions recruited from communities and companies across the country formed groups as a cluster randomization unit. The data of annual health checkups obtained from each group are utilized for identifying high-risk individuals and followup. This paper presents the study protocol in detail, including the rationale and the recruitment results. As a national project, this information should be widely referred to and shared by researchers and practitioners in preventive medicine.

\section{Methods}

This study has been approved by the Ethical Committee of the Japan Foundation for the Promotion of International Medical Research Cooperation (National Center for Global Health and Medicine, Tokyo, Japan).

\section{Study design}

The present study is a cluster randomized controlled trial $[19,20]$ aimed at involving Japanese men and women, aged 20-65 years, at high risk for developing T2DM. For the recruitment of study subjects and their follow-up, we employ health checkups conducted annually by health care divisions at communities and worksites. A total of 17 health care divisions were enrolled across the country. Large health care divisions, with a large number of examinees and branches covering different areas, were divided into groups. A total of 43 groups were thus formed from 17 health care divisions, with each group having approximately 1,000-6,000 annual health checkup examinees. For the cluster randomization, these groups were randomly allocated to either an intervention or a control arm. Using the 2006 health checkup data obtained from each cluster, lifestyle support centers sent a program kit to the candidates who met the eligibility criteria and invited them to participate in the study. The kit included an explanation about the study's aims and protocol, a consent form, and a questionnaire regarding lifestyle and health status. Those 
who consented to participate and completed the questionnaire were registered as study participants at lifestyle support centers, after their eligibility was checked based on their self-reported health status. Subjects in the intervention arm will receive non-face-to-face intervention via telephone or mobile-phone over the course of one year. Subjects in control arm will receive no such intervention. The progression to diabetes will be monitored by an annual health checkup and questionnaire over three years. All data for the study are collected at the lifestyle support centers and sent to the data management center in a de-identified form.

\section{Recruitment of health care divisions}

By advertising on the internet or by direct contact, we invited health care divisions at communities and companies to participate in the study. The inclusion criteria for the participating health care division were; 1) it conducts health checkups according to guidelines by the Health Promotion Law, 2) as a rule it has 2,000 or more examinees annually, 3) it can provide the study group with health checkups data every year starting from 2006, and 4) it can conduct lifestyle survey every year using a questionnaire prepared by the study team. Health care divisions, in which study team members are directly involved as industrial physicians, were excluded. Seventeen health care divisions, widely distributed throughout the country, agreed to participate in the study. Among them 14 health care divisions belonged to companies, 2 to municipalities, and 1 was a mixture of small-sized companies and municipalities. They were all approved by the steering committee. A large health care division, covering many distant areas, was divided into groups. This process was done by the health care division itself mainly based on the area and number of examinees. A total of 43 groups were thus formed from 17 health care divisions. The number of groups formed in each health care division ranged from 1 to 10 . Each group included 700 to 6,000 annual examinees. Some groups that were small were pooled with others. Using the results of health checkups in 2006, candidates who met inclusion criteria (described later) were identified in each group.

\section{Randomization}

For cluster randomization, the groups were randomly allocated to either an intervention $(n=22)$ or a control $(n=21)$ arm. Randomization was performed 3 times according to 3 recruitment periods (March to April, May to June, and July to August in 2007). When two or more groups were made from one health care division, they were allocated to each of the arms within the health care division. Some small groups were pooled with others. Allocation was carried out using stratified randomization with seven strata of companies or communities in the first period, five strata in the second period, and three strata in the third period. A randomization list was prepared by an independent statistician using the SAS PLAN procedure with seed $=4989$. This procedure was conducted using SAS version 9.1 (SAS Inc., Cary, NC, USA). Simple randomization was performed with 2 levels of treatment. The groups were notified of their allocation status before study subjects were recruited. The subjects were notified of their allocation status when they were recruited.

\section{Health checkups}

Guidelines for health check implementation were an nounced in 2004 based on the Health Promotion Law. In 2006 mandatory items to be checked included 1) anamnesis of past history including history of medication and smoking, 2) subjective and objective symptoms, 3) body height and weight, 4) Body Mass Index (BMI), calculated as body weight $(\mathrm{kg})$ divided by square of body height $\left.\left(\mathrm{m}^{2}\right), 5\right)$ blood pressure, 6) serum alanine aminotransferase, asparate aminotransferase and gamma glutamyltranspeptidase, 7) serum triglycerides, HDL cholesterol and LDL cholesterol, 8) fasting plasma glucose, and 9) urinalysis. At health checkup sites anthropometric measurements were done by public health nurses or industrial nurses. Height was measured in the standing position by public health nurses or industrial nurses. Weight was measured without shoes or heavy clothes to the nearest $0.1 \mathrm{~kg}$ using standard calibrated scales. Systolic and diastolic blood pressure values were measured in the sitting position [21]. Blood was withdrawn after 8 hours of fasting and analyzed with standard methods in clinical laboratories under the nationally certified laboratory management system. If blood was withdrawn from people who had not fasted, plasma glucose data was treated as casual plasma glucose and triglycerides values were omitted from the analysis. We did not perform any additional tests for this study.

\section{Inclusion and exclusion criteria for study subjects}

Using the 2006 year health checkups data, candidates who met the inclusion criteria were identified in each cluster. Inclusion criteria included an age of 20-65 years and impaired fasting glucose (IFG) defined as a fasting plasma glucose concentration (FPG) of $100-125 \mathrm{mg} / \mathrm{dL}$ (5.6-6.9 $\mathrm{mmol} / \mathrm{L})$. In the 2006 year health checkups, however, blood sampling was not always done in the fasting state. In those individuals where the FPG was not available, plasma glucose concentrations (casual plasma glucose, CPG) of $118-143 \mathrm{mg} / \mathrm{dL}$ (6.6-7.9 $\mathrm{mmol} / \mathrm{L})$ $[22,23]$ were considered eligible. A CPG $\geq 11.1 \mathrm{mmol} / \mathrm{l}$ $(200 \mathrm{mg} / \mathrm{dl})$ indicates diabetic type of glucose tolerance according to the report of the committee on the classification and diagnostic criteria of diabetes mellitus 
[24,25]. A CPG is also used as the risk assessment for cardiovascular disease in Japan [26]. Exclusion criteria included diagnosed diabetes, a previous history of diabetes taking anti-diabetic agents, a HbA1c of $\geq 6.5 \%$ [27]. Women with a history of gestational diabetes could be enrolled. Physical or medical conditions that do not allow exercise, pregnancy or possible pregnancy, evidence for of type 1 diabetes mellitus, liver cirrhosis or chronic viral hepatitis (type B or type C), and use of a cardiac pacemaker were also included as exclusion criteria. We also excluded those who had already participated in other lifestyle modification programs and those who could not obtain the approval from their doctors.

\section{Enrollment of the study subject}

We outsourced some parts of the study works to three existing private companies (Tokio Marine \& Nichido Medical Service Co., Ltd., National Education Association, INC. VISIT HEALTH Co., Ltd., and Meiji Yasuda System Technology Co., Ltd., Japan). They were all practicing healthcare services. They participate in this study as a lifestyle support center, which managed the recruitment and enrollment of study subjects and the lifestyle intervention. The lifestyle support center sent a program kit by mail to the eligible subjects in each cluster, inviting them to participate in the study. The kit included an explanation about the study's aims and protocol, a consent form, and a questionnaire regarding lifestyle and health status. Those who consented to participate and completed the questionnaire were enrolled as study participants at the lifestyle support center, after their eligibility was checked based on their self-reported present and past health conditions and, when available, based on information from physicians in the health care divisions.

\section{Characteristics of study subjects}

As mentioned above, using a questionnaire, subjects in both the intervention and control arms were asked about their lifestyle (diet, exercise habits, and smoking history) and present and past health conditions. They were categorized into following groups by their BMI, based on the WHO Western Pacific Regional Office (WPRO) criteria; <18.5 as "Underweight", 18.5 to 22.9 as "Normal", 23.0 to 24.9 as "Overweight", 25.0 to 29.9 as "Obese I", and $\geq 30.0$ as "Obese II" $[28,29]$. To define the Metabolic Syndrome in this study we used the modified criteria of the third report of the National Cholesterol Education Program Expert Panel on Detection, Evaluation, and Treatment of High Cholesterol in Adults (NCEP/ATPIII) [30,31]. When three or more of the following components were present in an individual, the individual was judged to have the Metabolic Syndrome: 1) serum triglycerides $\geq 150 \mathrm{mg} / \mathrm{dL}[\geq 1.69 \mathrm{mmol} / \mathrm{L}]$;, 2) HDL-cholesterol $<40 \mathrm{mg} / \mathrm{dL}[<1.04 \mathrm{mmol} / \mathrm{L}]$ for men and $<50 \mathrm{mg} / \mathrm{dL}$ [ $<1.29 \mathrm{mmol} / \mathrm{L}]$ for women, 3) fasting plasma glucose $\geq 100 \mathrm{mg} / \mathrm{dL}[\geq 5.6 \mathrm{mmol} / \mathrm{L}], 4)$ blood pressure $\geq 130 / 85 \mathrm{mmHg}$, or use of blood pressure lowering agents, and 5) a BMI of $\geq 25 \mathrm{~kg} / \mathrm{m}^{2}$ [32]. In 2006, when the baseline data were obtained, waist size was not measured in the majority of the health checkup sites. Therefore, BMI was substituted for waist circumference.

\section{Goals for lifestyle changes}

The goals for lifestyle change are set for each subject from the following four points; 1) habitual exercise (10,000 steps or more per day or 60 min or more per week of accumulated moderate levels of exercise), 2) achievement and maintenance of an appropriate body weight (a $5 \%$ reduction in body weight in subjects with a BMI of $\geq 25 \mathrm{~kg} / \mathrm{m}^{2}$ or a $3 \%$ reduction in subjects with a BMI of $23.0-24.9 \mathrm{~kg} / \mathrm{m}^{2}$ ), 3) habitual intake of dietary fiber (five or more dishes of vegetables per day or $350 \mathrm{~g}$ or more of vegetables per day ), and 4) restrictions on alcohol intake (1 "go" $(180 \mathrm{ml})$ or less per day in terms of Japanese sake. 1 "go" of Japanese sake contains $23 \mathrm{~g}$ of ethanol [33]).

\section{Lifestyle intervention}

After setting goals, the intervention and control arms will receive different treatments. For subjects in the control arm, a weight scale (HBF-354 IT-2; Omron Healthcare Co., Ltd., Japan) and a pedometer (HJ-710 IT; Omron Healthcare Co., Ltd., Japan) with a storage function are provided. They will periodically receive newsletters from the lifestyle support center, which run healthrelated information and messages to encourage them to undergo a health checkup regularly. These are done to minimize the potential for greater attrition from subjects in the control arm. For the subjects in the intervention arm, in addition to the services provided to the control arm, telephone-delivered lifestyle support will be provided over a one-year period through one of the three lifestyle support centers. In addition to phone calls, written information delivered by mail is also used. Subjects monitor achievement of their own personal action plan. They are encouraged to measure body weight and the number of footsteps every day and send the accumulated data to the lifestyle support center monthly via a transmitter (DC-100; JMS Co., Ltd., Japan). The staff will monitor the achievement of subject's goals regularly and give advice by phone or mail (Figure 1). As mentioned before the intervention is outsourced to private companies. Because the sample size is large, we use three companies. The National Education Association, INC. VISIT HEALTH Co., Ltd., Ltd., Meiji Yasuda System Technology Co., Ltd., and Tokio Marine \& Nichido Medical Service Co., Japan will manage 16, 18 and 9 groups, respectively. All study subjects in each group will be 


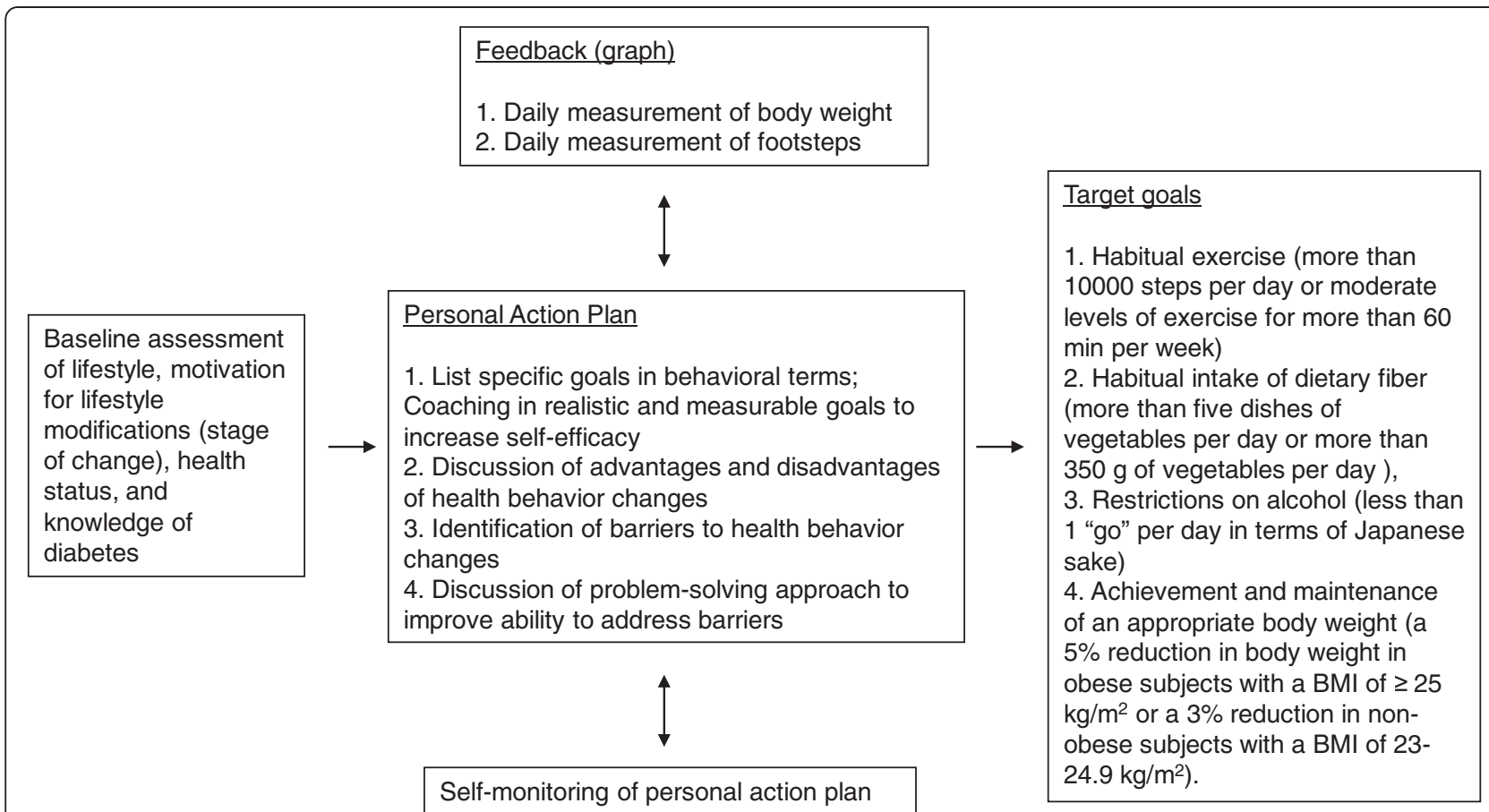

Figure 1 Telephone-delivered lifestyle modification support model: theory matrix.

managed by the same company. We do not standardize the intervention program. Each company uses its own intervention schedule approved by the study group (Table 1). The intervention is standardized within each company. Public health nurses and registered dieticians employed by the lifestyle support centers have college degree and at least 5 years work experience of the intervention. In addition, we will hold educational sessions on diabetes and its prevention for them and training sessions to improve their skills of telephone counseling with motivational interviewing. As shown in the Table 1, there are considerable differences in the quantity of services among the companies. Participants will receive phone calls at least 3 times, and at most 10 times, over one year with the length of each call being between 15-30 minutes.

\section{Follow-up and outcome}

Participants will be followed up over a three- year period using data from an annual health checkup and a questionnaire regarding health and lifestyle. The questionnaires are mailed out to the participants from the lifestyle support center with self-addressed envelopes. If a completed questionnaire is not sent back to the lifestyle support center within two weeks, the lifestyle support center will contact the participant first by mail and then by telephone. We made a manual for this process. The primary outcome is the development of diabetes in

Table 1 Schedules of telephone counseling of the three lifestyle support centers

\begin{tabular}{|c|c|c|c|}
\hline & $\begin{array}{l}\text { National Education Association INC. } \\
\text { VISIT HEALTH }\end{array}$ & $\begin{array}{l}\text { Meiji Yasuda System } \\
\text { Technology }\end{array}$ & $\begin{array}{l}\text { Tokio Marine \& Nichido } \\
\text { Medical Service }\end{array}$ \\
\hline Introduction and welcome call & In Week 1 & In Month 2 & In Month 3 \\
\hline Support calls & In Months 2, 3, 4, 7, and 10. & $\begin{array}{l}\text { In Months 3, 4, 5, 6, 7, 8, 9, } \\
\text { 10, and } 11 .\end{array}$ & In Months 7 and 12 \\
\hline Advice sheets by mail & No & Monthly, during Month 2-12 & Monthly, during Month 2-12 \\
\hline $\begin{array}{l}\text { Feedback by graph (body weight and } \\
\text { footsteps) }\end{array}$ & Monthly & Monthly & Monthly \\
\hline $\begin{array}{l}\text { The number of groups in the control/ } \\
\text { intervention arm }\end{array}$ & $8 / 8$ & $8 / 7$ & $4 / 5$ \\
\hline The number of subjects in the control & $595 / 722$ & $413 / 484$ & $328 / 298$ \\
\hline
\end{tabular}

Data are $\mathrm{n}$. 
participants whose FPG concentration is $100-125 \mathrm{mg} / \mathrm{dL}$ (5.6-6.9 $\mathrm{mmol} / \mathrm{L})$ at baseline. The development of diabetes is defined as; \#1) a rise in FPG to a level equal to or greater than $126 \mathrm{mg} / \mathrm{dL}(7.0 \mathrm{mmol} / \mathrm{L})$ as revealed in the follow-up annual health checkup, and \#2) a diagnosis of diabetes or use of anti-diabetic drugs as reported in the annual questionnaire with confirmation by referring to medical records. Other outcomes are changes in body weight, BMI, plasma glucose, blood pressure, serum lipids, HbA1c, the percentage of subjects with the Metabolic Syndrome, lifestyle, and the development of cardiovascular diseases.

\section{Dropout and discontinuance}

Dropout cases in the present study include; 1) participants who have not undergone an annual health checkup after enrollment, and 2) participants who have lost contact with the study team. Discontinuous cases are defined as; 1) participants who have developed adverse events that make continuance impossible, 2) participants who request to discontinue, 3) participants who are judged inappropriate for continuing the study by the project leader for various reasons.

\section{Data management}

Data management is outsourced to CIMIC Co., Ltd., Japan, a contract research organization offering clinical research management services. All data obtained in the study will be stored in de-identified forms in the data management center and used in conformity with the study aims only. The project leader (HK) has overall responsibility for management of the study data.

\section{Blinding}

Study participants and the staff members are not blinded to the study arm status. Analysts who perform final data analysis will be blinded.

\section{Sample size}

The present study is likely to observe a significantly longer diabetes-free period in the intervention than in the control arm. Thus, the null hypothesis is that the diabetes-free period in the intervention arm is the same as that in the control arm. The sample size(S) needed is calculated using the formula $[34,35] ; S=(1+$ [cluster size -1$] \times \mathrm{ICC}) \times \mathrm{N}$, where $\mathrm{N}$ represents the sample size required when study subjects are randomized individually, and ICC represents an intra-cluster coefficient [36]. Based on the available prospective data from Japanese population the yearly incidence of diabetes among high-risk group varies between 2 and $7 \%[37,38]$. When calculated on the assumption that the annual incidence of diabetes is $4 \%$ in the control arm and the intervention reduces the incidence by $50 \%, \mathrm{~N}$ will be 1100 with an alpha of $5 \%$ and a power of $90 \%$ according to Shoenfeld \& Richter [34]. When the ICC and the cluster size (number of individuals in each cluster) are assumed to be 0.02 and $60, \mathrm{~S}$ and the number of clusters will be 2398 and 40, respectively. Assuming that the dropout rate is $30 \%, 3426$ subjects are needed. On the assumption that 1) the prevalence of high-risk individuals in each cluster is $10 \%$, and 2) $30 \%$ of eligible subjects consent to participate in the study, the total number of health checkup examinees required would be approximately 114,200 , and the number of health checkup examinees in each cluster will be approximately 2900 . For descriptive analyses of the diabetes-free duration, the Kaplan-Meier method is used.

\section{Statistical analyses}

The analyses are done using Statistical Package for Social Science software version 19.0 (SPSS Inc., Chicago, IL, USA) or SAS version 9.3 (SAS Inc., Cary, NC, USA). The analysis will be done on an intention to treat basis. Survival curves for the development of diabetes will be estimated by the Kaplan-Meier method. The log rank test will be also conducted. We will take into account the clustering effect in the main outcome analysis and sub-analysis using the LWA model (Lee, Wei and Amato) [39-41]. Cox regression analysis will be used to calculate the unadjusted and adjusted HRs and 95\% CIs for arm and risk factors. In multivariable Cox analysis, all significant variables selected for the univariate analysis will be used with the criterion of $\mathrm{p}<0.1$. Student's t-test (or Mann-Whitney U-test according to the frequency distribution of the variable) will be used to compare the means (or the distribution) of the two study arms for continuous variables. Chi-square test or chisquare for trend will be used to compare proportions for categorical variables. We do not adjust for the clustering effect for analysis of the secondary outcome. Those cases with missing data will be simply omitted in the relevant analysis. A $\mathrm{p}$ value less than 0.05 is considered significant.

\section{Results}

Forty-three groups, formed from 17 health care divisions at companies or communities across the country, were randomly assigned to a control arm (21 groups) or an intervention arm (22 groups) between March 2007 and February 2008. Figure 2 shows the flow of recruitment of study subjects through annual health checkups. Approximately 230, 000 individuals (male $85 \%$ ) underwent health checkups by those 43 groups in 2006. Among them, 14,473 subjects (7494 in the control and 6979 in the intervention arm) met the inclusion criteria and received an invitation letter to participate in the study. As a result 1643 subjects from the control and 1491 subjects from the intervention arm consented to participate. 


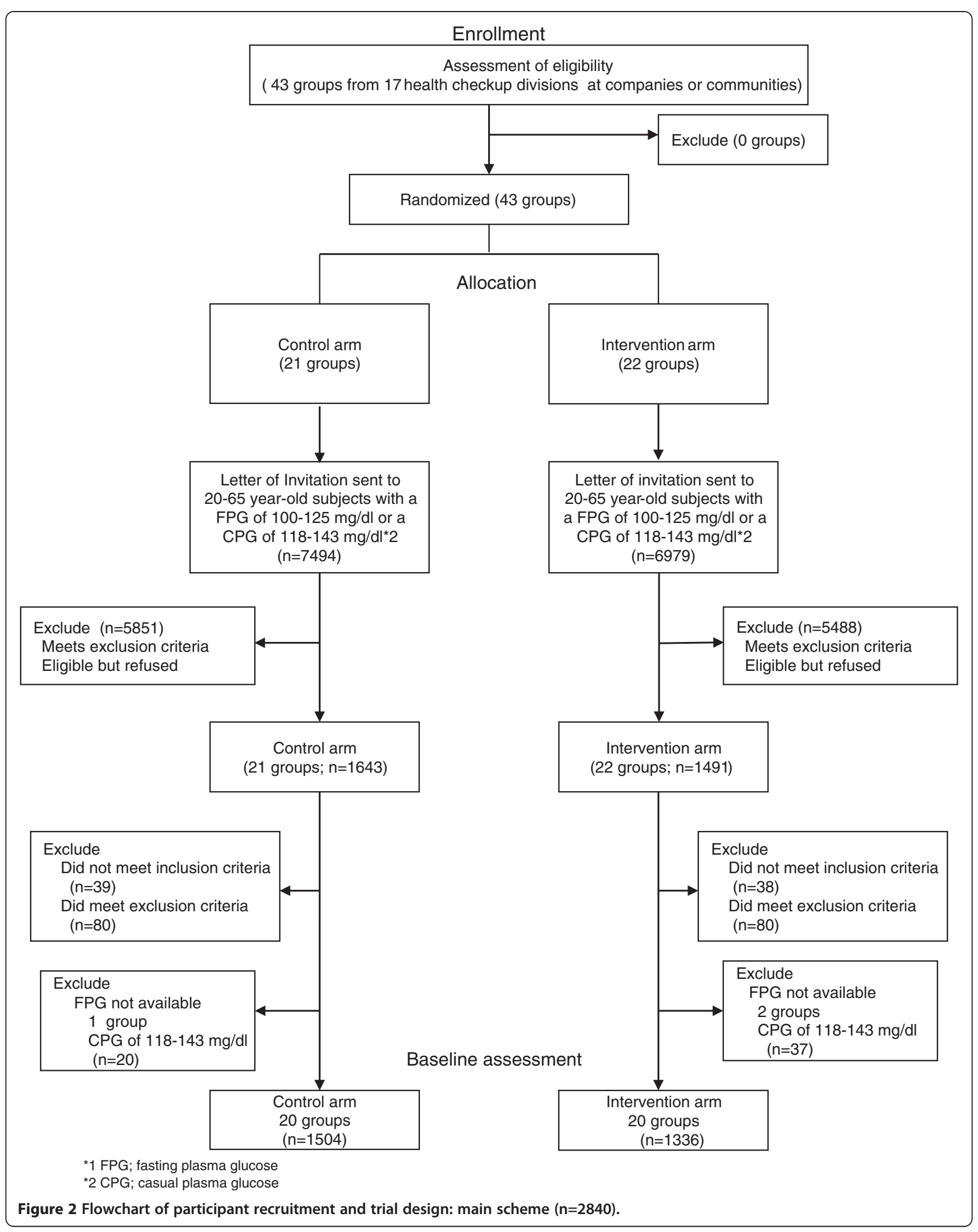


Finally, 2897 subjects were enrolled, with 1524 in the control and 1336 in the intervention arm. The overall consent rate of the study was approximately $20 \%$ with no difference between the study arms. Among the 2897 subjects, 57 subjects (20 in the control and 37 in the intervention arm) were enrolled with CPG of $118-143 \mathrm{mg} / \mathrm{dL}$ 6.6-7.9 mmol/L). As shown in Figure 2, those subjects are not included for the main outcome analysis. The remaining 1504 in the control and 1336 in the intervention arm will be followed up for the development of diabetes (primary outcome). The median (interquartile range) of the group size in the control arm before and after screening for eligibility was 301 (200-442) and 61 (35-88), respectively and those in the intervention arm was 313 (158-587) and 60 (41-94), respectively. There is no difference in group size between arms. In one group in the control and two groups in the intervention arm no participants were enrolled with FPG. Those three groups were not included in the calculation of cluster size. The number of company settings, community settings, and mixed settings in the intervention arm were 16,3 , and 1 , respectively. The number of company settings, community settings, and mixed settings in the control arm were 15 , 3 , and 2 , respectively. There were no differences between the arms in the characteristic of the participants in terms of age, sex ratio, FPG levels, BMI, and the prevalence of obesity (Table 2). No difference was found in the prevalence of the Metabolic Syndrome, either (Table 3). All follow-up data will be collected by winter 2012.

\section{Discussion}

We have launched this J-DOIT1 trial to test whether goal-focused lifestyle support delivered by healthcare providers via the telephone is feasible and effective for preventing or delaying the development of T2DM in high-risk individuals. Statutory health checkup programs, provided annually by public medical care insurance, would offer significant advantages for carrying out this study. Thus, for the recruitment of study subjects and their follow-up, biochemical and anthropometric data are all obtained from health checkup sites.

\section{Cluster randomization}

In recently reported lifestyle intervention studies, both individual randomization and cluster randomization $[42,43]$ have been used. The cluster randomization design has the advantages of administrative convenience, ease of obtaining the cooperation of investigators, enhancement of subject compliance, and avoidance of treatment contamination. Since study subjects in this trial are employees of the same workplaces or inhabitants of the same communities, we chose cluster randomization to avoid diluting the effect of the intervention. The contamination could occur with individual randomization e.g. by control subjects receiving part of the intervention in a shared environment. Generally, cluster randomized trials, are susceptible to a range of methodological problems including selection bias [18]. Selection bias can be avoided by recruiting and enrolling the study subjects into the study before the groups are allocated to the study arms [44]. In our study design,

Table 2 Participant characteristics by randomized intervention assignment

\begin{tabular}{|c|c|c|}
\hline Variables & Control arm & Intervention arm \\
\hline & $(n=1504)$ & $(n=1336)$ \\
\hline Age, years & $49(44-54)$ & $49(44-55)$ \\
\hline Male, $\%$ & 85.0 & 83.8 \\
\hline Body mass index, $\mathrm{kg} / \mathrm{m}^{2}$ & $24.0(22.3-25.8)$ & $24.2(22.3-26.3)$ \\
\hline \multicolumn{3}{|l|}{ WRPO criteria* } \\
\hline Underweight (less than 18.5 BMI),\% & 2.1 & 1.8 \\
\hline Normal (18.5-22.9 BMI),\% & 33.2 & 31.1 \\
\hline Overweight (23.0-24.9 BMI),\% & 28.4 & 28.1 \\
\hline Obesity I (25.0-29.9 BMI),\% & 32.0 & 33.7 \\
\hline Obesity II (Over 30.0 BMI),\% & 4.3 & 5.4 \\
\hline Systolic blood pressure, $\mathrm{mmHg}$ & $125(114-136)$ & $125(116-135)$ \\
\hline Diastolic blood pressure, $\mathrm{mmHg}$ & $80(71-87)$ & $79(72-87)$ \\
\hline Total cholesterol, $\mathrm{mmol} / \mathrm{l}$ & $5.4(4.9-6.0)$ & $5.5(4.8-6.1)$ \\
\hline HDL-cholesterol, mmol// & $1.5(1.3-1.8)$ & $1.5(1.2-1.8)$ \\
\hline Triglyceride, $\mathrm{mmol} / / \mathrm{l}$ & $1.3(0.9-1.9)$ & $1.3(0.9-1.8$ \\
\hline
\end{tabular}

Values are median (interquartile range or percentage. ${ }^{*}$ The subjects were categorized into following groups based on the WHO West Pacific Regional Office (WPRO) criteria; less than 18.5 BMI, as "Underweight", 18.5 to 22.9 as "Normal", 23.0 to 24.9 as "Overweight", 25.0 to 29.9 as "Obese I" and over 30.0 BMI as "Obese II". 
Table 3 Components of metabolic syndrome by randomized intervention assignment and sex

\begin{tabular}{|c|c|c|c|c|c|c|c|c|}
\hline \multirow[t]{2}{*}{ Variables } & \multicolumn{4}{|c|}{ Control arm } & \multicolumn{4}{|c|}{ Intervention arm } \\
\hline & \multicolumn{2}{|c|}{ Men } & \multicolumn{2}{|c|}{ Women } & \multicolumn{2}{|c|}{ Men } & \multicolumn{2}{|c|}{ Women } \\
\hline & \multicolumn{2}{|c|}{$(n=1279$} & \multicolumn{2}{|c|}{$(n=225)$} & \multicolumn{2}{|c|}{$(n=1119)$} & \multicolumn{2}{|c|}{$(n=217)$} \\
\hline 1. $\mathrm{BMI} \geq 25 \mathrm{~kg} / \mathrm{m}^{2}$ & 479 & $37.5 \%$ & 67 & $29.8 \%$ & 456 & $40.8 \%$ & 66 & $30.4 \%$ \\
\hline 2. Hypertension & 580 & $45.3 \%$ & 75 & $33.3 \%$ & 514 & $45.9 \%$ & 66 & $30.4 \%$ \\
\hline 3. TG $\geq 150 \mathrm{mg} / \mathrm{dl}$ & 429 & $33.5 \%$ & 30 & $13.3 \%$ & 360 & $32.2 \%$ & 29 & $13.4 \%$ \\
\hline 4. $\mathrm{HDL}<40 \mathrm{mg} / \mathrm{dl}$ in men, $<50 \mathrm{mg} / \mathrm{dl}$ in women & 77 & $6.0 \%$ & 27 & $12.0 \%$ & 76 & $6.8 \%$ & 24 & $11.1 \%$ \\
\hline 5. Hyperglycemia & 1279 & $100.0 \%$ & 225 & $100.0 \%$ & 1119 & $100.0 \%$ & 217 & $100.0 \%$ \\
\hline \multicolumn{9}{|l|}{ Risk factors of metabolic syndrome } \\
\hline 1 factor & 365 & $28.5 \%$ & 99 & $44.0 \%$ & 299 & $26.7 \%$ & 97 & $44.7 \%$ \\
\hline 2 factors & 416 & $32.5 \%$ & 71 & $31.6 \%$ & 359 & $32.1 \%$ & 66 & $30.4 \%$ \\
\hline$\geq 3$ factors & 496 & $38.8 \%$ & 55 & $24.4 \%$ & 459 & $41.0 \%$ & 53 & $24.4 \%$ \\
\hline
\end{tabular}

Data are number or percentage. Five subjects were excluded from the analyses because of missing data except for fasting plasma glucose.

however, the study subjects were recruited after the clusters were randomly allocated to the intervention or control arm. The reason for nor recruiting and enrolling subjects before randomization was that it was not practical due to the nature of the intervention, in which it takes too long to recruit individuals first. The individuals or the recruiters were not blinded to the allocation status. Careful attention should be paid to the likelihood of selection bias in our sample based on the cluster sizes between the two arms and comparison of the participants.

\section{Telephone-delivered interventions}

Structured intensive lifestyle modification can prevent T2DM in hospital and clinic settings [45-47], and primary healthcare settings [48]. To target young and middle-aged people, who are busy with work, this study employs a non face-to-face intervention using the telephone. Telephone-delivered intervention has a greater accessibility and potential availability of participants for the interview than face-to-face provided support. They facilitate, in a cost-effective manner [37], repeated contact and support for the participant necessary to promote maintenance of physical activity and diet. Thus telephone counseling would make it possible to deliver lifestyle intervention widely, at a low cost, but in a personalized way. There has been increasing interest in lifestyle support using the telephone [49-53]. However, it is unknown whether telephone-delivered support for lifestyle modification by healthcare providers is a feasible and effective way to prevent or delay the development of T2DM. If it is proved effective, lifestyle coaching by healthcare providers using telephone would be a promising tool for reducing the incidence of diabetes.

\section{Retention}

The final sample size (2840 participants) would provide $>80 \%$ power to detect a $50 \%$ reduction in the rate of development of T2DM among participants assigned to the lifestyle intervention with a $5 \%$ level of significance (two-sided), after no adjustment for losses in follow-up. The follow-up of participants is scheduled to finish in March 2012. Retention of participating health checkup facilities and subjects are critical for the success of this study. Drop-out rates are generally high in lifestyle programs conducted in primary healthcare clinical settings. To secure enough samples for analysis, participants are encouraged to attend an annual health checkup through a letter from the lifestyle support center. The lifestyle support center gives safety advice to prevent sport injuries which could lead to dropping out of the study.

\section{BMI and the Metabolic Syndrome}

We included not only overweight and obese subjects, but also subjects with a BMI of $<23 \mathrm{~kg} / \mathrm{m}^{2}$. Therefore, the BMI ranged widely from $<18.5$ to $>30$ in our study subjects with an average value of 24.3 . Only $39.0 \%$ of men and $30.1 \%$ of women had a BMI of $\geq 25 \mathrm{~kg} / \mathrm{m}^{2}$. Compared with western populations, obesity is less common in our general population [54]. It has also been reported that about $25 \%$ of subjects with impaired glucose tolerance have normal or even underweight categories of BMI [36]. It seems that the relationship between BMI and the risk of diabetes is not so straightforward in our population. Thus, we did not set eligibility criteria in terms of BMI. It would be of interest to study the incidence of diabetes and see what strategies are effective to prevent the development of diabetes in those with a lower BMI. In 2008, the concept of the Metabolic Syndrome was introduced in the health checkup program in our country [55]. Mukai et al. suggested that the Metabolic Syndrome significantly increased the risk of incident T2DM, irrespective of the presence or absence of impaired fasting glucose(IFG), and is therefore a valuable tool to identify individuals at high risk of T2DM in the general population in Japan 
[56]. In this study, we found $39.8 \%$ of men and $24.8 \%$ of women have $\geq 3$ risk factors for cardiovascular diseases, suggesting they have the Metabolic Syndrome. The present study would allow us to compare the incidence of T2DM in IFG subjects with or without the Metabolic Syndrome in a subanalysis.

\section{Limitations}

This study has several potential limitations. One is that we identified high risk subjects using fasting plasma glucose. We will follow them as to the development of diabetes using fasting plasma glucose determined at annual health checkups and a questionnaire. We do not add any other biochemical examinations such as the oral glucose tolerance test. Therefore, we may miss diabetic subjects having normal fasting but elevated $2 \mathrm{~h}$ plasma glucose levels [57-59]. We may also miss subjects with IGT, IFG and IGT, both associated with a substantially increased risk of developing diabetes, are considered to be of a different entity. In the majority of populations thus far studied, IGT is more prevalent than IFG. Thus, we must be careful in interpreting results. It is possible that the efficiency of identifying high-risk subjects will be increased by combining FPG and HbA1c data [60]. This study used results obtained in 2006 annual health checkups as baseline data. At that time, only $58.5 \%$ of participating checkup sites included the measurement of HbAlc as a health checkup item. Second, the present study lacks information on the use of drugs, such as fibrate, nicotinic acid, and fish oil, which affect the metabolism of HDL-cholesterol and triglycerides. This may have led us to underestimate the prevalence of the Metabolic Syndrome. Third, participants were predominantly from workplaces. We did not succeed in recruiting more participants from communities. Since men outnumber women in many workplaces in Japan, the study population was predominantly male. This bias may limit the generalizability of our results.

\section{Conclusions}

We have launched J-DOIT1, a nation-wide cluster randomized controlled trial to prevent development of T2DM in high-risk individuals using telephone-delivered intervention. Using annual health checkup data, a large cohort has been developed and successfully randomized. This trial is expected to contribute to evidence-based real-world preventive practices.

\section{Competing interests}

The authors declare that they have no competing interests.

\section{Authors' contributions}

$\mathrm{HK}$, the project leader, is involved in all aspects of the study. Kl, MK, NI, and MN designed the study, and prepared the protocol. NS, KK, YS, KT, and KO were involved in drafting the manuscript. KT, JS, SS and SM participated in statistical analysis. All authors have read and approved the final version of the manuscript.

\section{Acknowledgements}

The investigators gratefully acknowledge the health checkup divisions of the following companies and communities; Central Japan Railway Company, COOP Net, CSK Health Insurance Association, EAST JAPAN RAILWAY COMPANY, Hankyu Electric Railway Health Insurance Association, Health and Welfare Center (Atami), Hitachi Metals Health Insurance Society, Hitachi Transport System Health Insurance Association, JFE Steel Corporation., JTB

Management Service Corp., Kakogawa General Health Care Center, Koga Health Examination Center, Meidensha Health Insurance Association, Mitsui Life Insurance Company Ltd., Tokyo Electric Power Company, SHARP Health Insurance Association, and the Ube group (Ube City Office, Sanyo Onoda City Office, Tanabe Yamaguchi Pharma Factory Ltd., NISSAN Chemical Industries, Ltd., NIPPON KAYAKU CO., Ltd., Sanyo Onoda City Health Center) This study is funded by a Health and Labour Sciences Research Grant (Strategic Outcomes Research Program for Research on Diabetes and Comprehensive Research on Diabetes/Cardiovascular and Life-Style Related Diseases) from the Ministry of Health, Labour and Welfare of Japan.

\section{Author details}

${ }^{1}$ Division of Preventive Medicine, Clinical Research Institute, National Hospital Organization Kyoto Medical Center, Kyoto, Japan. ${ }^{2}$ Hyogo Health Service Association, Hyogo, Japan. ${ }^{3}$ Department of General Medicine/Family \& Community Medicine, Nagoya University Graduate School of Medicine, Nagoya, Japan. ${ }^{4}$ Department of Public Health, Nagoya City University Graduate School of Medical Sciences, Nagoya, Japan. ${ }^{5}$ Department of Biostatistics and Epidemiology, Yokohama City University, Yokohama, Japan. ${ }^{6}$ Office of Strategic Outcomes Research Program, Japan Foundation for the Promotion of International Medical Research Corporation, Tokyo, Japan. ${ }^{7}$ Department of Diabetes and Metabolic Medicine, National Center for Global Health and Medicine, Tokyo, Japan. ${ }^{8}$ Biostatistics, Biostatistics \& Programming Clinical Sciences \& Operation Research \& Development, Sanofi K.K, Tokyo, Japan. ${ }^{9}$ Diabetes Research Center, National Center for Global Health and Medicine, Tokyo, Japan. ${ }^{10}$ Koseikai Takeda Hospital, Kyoto, Japan.

Received: 10 February 2012 Accepted: 22 January 2013

Published: 29 January 2013

\section{References}

1. Neville SE, Boye KS, Montgomery WS, Iwamoto K, Okamura M, Hayes RP: Diabetes in Japan: a review of disease burden and approaches to treatment. Diabetes Metab Res Rev 2009, 25:705-716.

2. Hirose T, Kawamori R: Diabetes in Japan. Curr Diab Rep 2005, 5:226-9.

3. Outline of Results from 2007 National Health and Nutrition Survey: Outline of Results from 2007 National Health and Nutrition Survey. Tokyo: Annual Health, Labour and Welfare Report 2008-2009; 2009. http://www.mhlw.go. jp/english/wp/wp-hw3/dl/2-064_065.pdf.

4. Adachi M, Yamaoka K, Watanabe M, Nishikawa M, Hida E, Kobayashi I, Tango T: Effects of lifestyle education program for type 2 diabetes patients in clinics: study design of a cluster randomized trial. BMC Publ Health 2010, 10:742.

5. Tuomilehto J, Lindström J, Eriksson JG, Valle TT, Hämäläinen H, llanneParikka P, Keinänen-Kiukaanniemi S, Laakso M, Louheranta A, Rastas M, Salminen V, Uusitupa M: Finnish Diabetes Prevention Study Group: Prevention of type 2 diabetes mellitus by changes in lifestyle among subjects with impaired glucose tolerance. N Engl J Med 2001, 344:1343-1392.

6. Diabetes Prevention Program Research Group: Reduction in the incidence of type 2 diabetes with lifestyle intervention or metformin. N Engl J Med 2002, 346:393-403.

7. Yamaoka K, Tango T: Efficacy of lifestyle education to prevent type 2 diabetes: a meta-analysis of randomized controlled trials. Diabetes Care 2005, 28:2780-2786.

8. Cardona-Morrell M, Rychetnik L, Morrell SL, Espinel PT, Bauman A: Reduction of diabetes risk in routine clinical practice: are physical activity and nutrition interventions feasible and are the outcomes from reference trials replicable? A systematic review and meta-analysis. BMC Publ Health 2010, 10:653. 
9. Boltri JM, Davis-Smith YM, Seale JP, Shellenberger S, Okosun IS, Cornelius ME: Diabetes prevention in a faith-based setting: results of translational research. J Public Health Manag Pract 2008, 14:29-32.

10. Pagoto SL, Kantor L, Bodenlos JS, Gitkind M, Ma Y: Translating the diabetes prevention program into a hospital-based weight loss program. Health Psychol 2008, 27:S91-8.

11. Lipscomb ER, Finch EA, Brizendine E, Saha CK, Hays LM, Ackermann RT: Reduced 10-year risk of coronary heart disease in patients who participated in a community-based diabetes prevention program: the DEPLOY pilot study. Diabetes Care 2009, 32:394-396.

12. Whittemore R, Melkus G, Wagner J, Dziura J, Northrup V, Grey M: Translating the diabetes prevention program to primary care: a pilot study. Nurs Res 2009, 58:2-12.

13. Parikh P, Simon EP, Fei K, Looker H, Goytia C, Horowitz CR: Results of a pilot diabetes prevention intervention in East Harlem, New York City: Project HEED. Am J Public Health 2010, 100(Suppl 1):S232-9.

14. Jackson L: Translating the Diabetes Prevention Program into practice: a review of community interventions. Diabetes Educ 2009, 35:309-320.

15. Kudo Y, Miwa Y, Mikami J, Ohata T, Satoh T, Kido S, Sugiura Y, Tsunoda M, Aizawa Y: Predictors of Japanese workers' satisfaction with their annual health checkups. Ind Health 2009, 47:292-300.

16. Kohro T, Furui Y, Mitsutake N, Fujii R, Morita H, Oku S, Ohe K, Nagai R: The Japanese national health screening and intervention program aimed at preventing worsening of the metabolic syndrome. Int Heart J 2008, 49:193-203.

17. Yazaki Y, Kadowaki T: Combating diabetes and obesity in Japan. Nat Med 2006, 12:73-74.

18. Ahn C, Ahn D: Randomized Clinical Trials in Stroke Research. J Investig Med 2010, 58:277-281.

19. Campbell MK, Elbourne DR, Altman DG: CONSORT group: CONSORT statement: extension to cluster randomized trials. BMJ 2004, 328:702-708.

20. Murphy AW, Esterman A, Pilotto LS: Cluster randomized controlled trials in primary care: an introduction. Eur J Gen Pract 2006, 12:70-73.

21. Ohwaki K, Yano E: Body mass index as an indicator of metabolic disorders in annual health checkups among Japanese male workers. Ind Health 2009, 47:611-616.

22. Rolka DB, Narayan KM, Thompson TJ, Goldman D, Lindenmayer J, Alich K, Bacall D, Benjamin EM, Lamb B, Stuart DO, Engelgau MM: Performance of recommended screening tests for undiagnosed diabetes and dysglycemia. Diabetes Care 2001, 24:1899-1903.

23. Engelgau MM, Narayan KM, Herman WH: Screening for type 2 diabetes. Diabetes Care 2000, 23:1563-1580.

24. Kuzuya T, Nakagawa S, Satoh J, Kanazawa Y, Iwamoto Y, Kobayashi M, Nanjo K, Sasaki A, Seino Y, Ito C, Shima K, Nonaka K, Kadowaki T: Committee of the Japan Diabetes Society on the diagnostic criteria of diabetes mellitus. Report of the Committee on the classification and diagnostic criteria of diabetes mellitus. Diabetes Res Clin Pract 2002, 55(1):65-85.

25. Takahashi Y, Noda M, Tsugane S, Kuzuya T, Ito C, Kadowaki T: Prevalence of diabetes estimated by plasma glucose criteria combined with standardized measurement of $\mathrm{HbA} 1 \mathrm{c}$ among health checkup participants on Miyako Island, Japan. Diabetes Care 2000, 23(8):1092-1096.

26. NIPPON DATA80 Research Group: 19-year follow-up study of a Japanese representative population. Circ J 2006, 70(10):1249-1255.

27. Seino $Y$, Nanjo K, Tajima N, Kadowaki T, Kashiwagi A, Araki E, Ito C, Inagaki N, Iwamoto Y, Kasuga M, Hanafusa T, Haneda M, Ueki K: Report of the Committee on the ckassification and diagnostic criteria of diabetes mellitus. The Committee of the Japan Diabetes Society on the diagnostic criteria of diabetes mellitus. Diabetol Int 2010, 1:2-20

28. Anuurad E, Shiwaku K, Nogi A, Kitajima K, Enkhmaa B, Shimono K, Yamane $Y$ : The new BMI criteria for asians by the regional office for the western pacific region of $\mathrm{WHO}$ are suitable for screening of overweight to prevent metabolic syndrome in elder Japanese workers. J Occup Health 2003, 45:335-343.

29. Pan $W H$, Yeh WT: How to define obesity? Evidence-based multiple action points for public awareness, screening, and treatment: an extension of Asian-Pacific recommendations. Asia Pac J Clin Nutr 2008, 17:370-374.

30. Grundy SM, Brewer HB Jr, Cleeman Jl, Smith SC Jr, Lenfant C: Definition of metabolic syndrome: Report of the National Heart, Lung, and Blood Institute/American Heart Association conference on scientific issues related to definition. Circulation 2004, 109:433-438.
31. Alberti KG, Eckel RH, Grundy SM, Zimmet PZ, Cleeman II, Donato KA Fruchart JC, James WP, Loria CM, Smith SC Jr: Harmonizing the metabolic syndrome: a joint interim statement of the International Diabetes Federation Task Force on Epidemiology and Prevention; National Heart, Lung, and Blood Institute; American Heart Association; World Heart Federation; International Atherosclerosis Society; and International Association for the Study of Obesity. Circulation 2009, 120:1640-1645.

32. Nishina M, Nishina K, Ohira T, Makino K, Iso H: Associations of psychological distress with metabolic syndrome among Japanese urban residents. J Atheroscler Thromb 2011, 18:396-402.

33. Hata $Y$, Nakajima K: Life-style and serum lipids and lipoproteins. J Atheroscler Thromb 2000, 7:177-197.

34. Shoenfeld DA, Richter JR: Nomograms for calculating the number of patients needed for a clinical trial with survival as an endpoint. Biometrics 1982, 38:163-170.

35. Littenberg B, MacLean CD: Intra-cluster correlation coefficients in adults with diabetes in primary care practices: the Vermont Diabetes Information System field survey. BMC Med Res Methodol 2006, 6:20.

36. Killip S, Mahfoud Z, Pearce K: What is an intracluster correlation coefficient? Crucial concepts for primary care researchers. Ann Fam Med 2004, 2:204-208.

37. Ito C: Epidemiological study of diabetes mellitus in the Hiroshima area prevalence of diabetes mellitus and follow-up studies using the glucose tolerance test. Tohoku J Exp Med 1983, 141:115-118.

38. Ito C, Maeda R, Nakamura K, Sasaki H: Prediction of diabetes mellitus (NIDDM). Diabetes Res Clin Pract 1996, 34:S7-S11.

39. Lee EW, Wei LJ, Amato DA: Cox-type regression analysis for large number of small groups of correlated failure time observations. In Survival Analysis: State of the Art. Edited by Klein JP, Goel PK. Dordrecht, Netherlands: Kluwer Academic Publishers; 1992:237-247.

40. Mieno MN, Yamaguchi T, Ohashi Y: Alternative statistical methods for estimating efficacy of interferon beta- $1 \mathrm{~b}$ for multiple sclerosis clinical trials. BMC Med Res Methodol 2011, 11:80.

41. Wei LJ: The accelerated failure time model: a useful alternative to the Cox regression model in survival analysis. Stat Med 1992, 11:1871-1879.

42. Luoto R, Kinnunen TI, Aittasalo M, Kolu P, Raitanen J, Ojala K, Mansikkamäki K, Lamberg S, Vasankari T, Komulainen T, Tulokas S: Primary prevention of gestational diabetes mellitus and large-for-gestational-age newborns by lifestyle counseling: a cluster-randomized controlled trial. PLOS Med 2011, 8:e1001036.

43. HEALTHY Study Group, Foster GD, Linder B, Baranowski T, Cooper DM, Goldberg L, Harrell JS, Kaufman F, Marcus MD, Treviño RP, Hirst K: A school-based intervention for diabetes risk reduction. N Engl J Med 2010, 363:443-453.

44. Eldridge $S$, Kerry S, Torgerson DJ: Bias in identifying and recruiting participants in cluster randomised trials: what can be done? BMJ 2010, 340:36-39.

45. Kosaka K, Noda M, Kuzuya T: Prevention of type 2 diabetes by lifestyle intervention: a Japanese trial in IGT males. Diabetes Res Clin Pract 2005 67:152-162.

46. Kawahara T, Takahashi K, Inazu T, Arao T, Kawahara C, Tabata T, Moriyama H, Okada Y, Morita E, Tanaka Y: Reduced progression to type 2 diabetes from impaired glucose tolerance after a 2-day in-hospital diabetes educational program: the Joetsu Diabetes Prevention Trial. Diabetes Care 2008, 31:1949-1954

47. Saito $T$, Watanabe $M$, Nishida J, Izumi T, Omura M, Takagi T, Fukunaga R, Bandai $Y$, Tajima N, Nakamura $Y$, Ito M: Zensharen Study for Prevention of Lifestyle Diseases Group. Lifestyle modification and prevention of type 2 diabetes in overweight Japanese with impaired fasting glucose levels: a randomized controlled trial. Arch Intern Med 2011, 171:1352-1360.

48. Sakane N, Sato J, Tsushita K, Tsujii S, Kotani K, Tsuzaki K, Tominaga M, Kawazu S, Sato Y, Usui T, Kamae I, Yoshida T, Kiyohara Y, Sato S, Kuzuya H: Prevention of type 2 diabetes in a primary healthcare setting: Three-year results of lifestyle intervention in Japanese subjects with impaired glucose tolerance. BMC Publ Health 2011, 11:40.

49. Graves N, Barnett AG, Halton KA, Veerman JL, Winkler E, Owen N, Reeves MM, Marshall A, Eakin E: Cost-effectiveness of a telephone-delivered intervention for physical activity and diet. PLoS One 2009, 4:e7135.

50. van Wier MF, Ariëns GA, Dekkers JC, Hendriksen IJ, Smid T, van Mechelen W: Phone and e-mail counselling are effective for weight management in 
an overweight working population: a randomized controlled trial. BMC Publ Health 2009, 9:6.

51. Dale J, Caramlau I, Docherty A, Sturt J, Hearnshaw H: Telecare motivational interviewing for diabetes patient education and support: a randomized controlled trial based in primary care comparing nurse and peer supporter delivery. Trials 2007, 8:18.

52. Eakin EG, Reeves MM, Marshall AL, Dunstan DW, Graves N, Healy GN, Bleier J, Barnett AG, O'Moore-Sullivan T, Russell A, Wilkie K: Living Well with Diabetes: a randomized controlled trial of a telephone-delivered intervention for maintenance of weight loss, physical activity and glycaemic control in adults with type 2 diabetes. BMC Publ Health 2010, 10:452.

53. Hunkeler EM, Meresman JF, Hargreaves WA, Fireman B, Berman WH, Kirsch AJ, Groebe J, Hurt SW, Braden P, Getzell M, Feigenbaum PA, Peng T, Salzer M: Efficacy of nurse telehealth care and peer support in augmenting treatment of depression in primary care. Arch Fam Med 2000, 9:700-708.

54. Funatogawa I, Funatogawa T, Nakao M, Karita K, Yano E: Changes in body mass index by birth cohort in Japanese adults: results from the National Nutrition Survey of Japan 1956-2005. Int J Epidemiol 2009, 38:83-92.

55. Nakashima N, Kobayashi K, Inoguchi T, Nishida D, Tanaka N, Nakazono H, Hoshino A, Soejima H, Takayanagi R, Nawata H: A Japanese model of disease management. Stud Health Technol Inform 2007, 129(Pt 2):1174-8.

56. Mukai N, Doi Y, Ninomiya T, Hata J, Yonemoto K, Iwase M, lida M, Kiyohara $Y$ : Impact of metabolic syndrome compared with impaired fasting glucose on the development of type 2 diabetes in a general Japanese population: the Hisayama study. Diabetes Care 2009, 32:2288-2293.

57. Unwin N, Shaw J, Zimmet P, Alberti KG: Impaired glucose tolerance and impaired fasting glycaemia: the current status on definition and intervention. Diabet Med 2002, 19:708-723.

58. Gabir MM, Hanson RL, Dabelea D, Imperatore G, Roumain J, Bennett PH, Knowler WC: The 1997 American Diabetes Association and 1999 World Health Organization criteria for hyperglycemia in the diagnosis and prediction of diabetes. Diabetes Care 2000, 23:1108-1112.

59. Bartoli E, Fra GP, Carnevale Schianca GP: The oral glucose tolerance test (OGTT) revisited. Eur J Intern Med 2011, 22:8-12.

60. Heianza Y, Hara S, Arase Y, Saito K, Fujiwara K, Tsuji H, Kodama S, Hsieh SD, Mori Y, Shimano H, Yamada N, Kosaka K, Sone H: HbA1c 5.7-6.4\% and impaired fasting plasma glucose for diagnosis of prediabetes and risk of progression to diabetes in Japan (TOPICS 3): a longitudinal cohort study. Lancet 2011, 378:147-155.

doi:10.1186/1471-2458-13-81

Cite this article as: Sakane et al:: Japan Diabetes Outcome Intervention Trial-1(J-DOIT1), a nationwide cluster randomized trial of type 2

diabetes prevention by telephone-delivered lifestyle support for highrisk subjects detected at health checkups: rationale, design, and recruitment. BMC Public Health 2013 13:81.

\section{Submit your next manuscript to BioMed Central and take full advantage of:}

- Convenient online submission

- Thorough peer review

- No space constraints or color figure charges

- Immediate publication on acceptance

- Inclusion in PubMed, CAS, Scopus and Google Scholar

- Research which is freely available for redistribution 